\title{
Aggressive Awareness Campaigns May Not be Enough for HIV Prevention in Prisons-Studies in Zambia Suggest Time for Evidence Based Interventions
}

\author{
Oscar O. Simooya ${ }^{*}, 1$, Nawa Sanjobo ${ }^{1}$, Chanda Mulenga ${ }^{2}$, David Mwakazanga ${ }^{2}$, Frank Tailoka ${ }^{3}$, \\ Evans Betha ${ }^{2}$, Lovemore Kaetano ${ }^{2}$ and Harold Witola ${ }^{4}$
}

${ }^{I}$ IN BUT FREE Prisons Project, P.O. Box 22521, Kitwe, Zambia

${ }^{2}$ Tropical Diseases Research Centre, P.O. Box 71769, Ndola, Zambia

${ }^{3}$ Copperbelt University, P.O. Box 21692, Kitwe, Zambia

${ }^{4}$ National HIV/AIDS/STI/TB Council, P.O. Box 38718, Lusaka, Zambia

\begin{abstract}
Background: More than thirty years into the epidemic and at a time of declining HIV prevalence rates in many affected regions, prisoners continue to receive less protection against HIV infection compared to communities outside. This survey, the third since 1988 was conducted to assess the effectiveness of current programmes in Zambian prisons.

Methods: From June 2009-June 2010, 2,244 \{184 women (8.2\%); 2060 men (91.8\%)\} prisoners in Zambia participated in a survey of HIV prevalence and risk behaviours. Risk behaviours were elicited using a pretested questionnaire whilst HIV prevalence was determined using two ELISAs and Western Blot. The survey was voluntary, anonymous and confidential.

Results: Six hundred and nine (609), (27\%), prisoners were found with HIV infection. This was associated with age, highest in those $35-44$ years and gender, $47.3 \%$ of the women tested were positive for HIV. Other significant associations were found between HIV and tattooing, STIs and TB. Only 35 prisoners agreed to have had male to male sex (MSM) and this was not linked to HIV result. However, indirect questioning suggested much higher figures of MSM in prisons. Overall, prisoners had knowledge about HIV and over $60 \%$ knew their HIV status.

Conclusion: The HIV prevalence rate of $27 \%$ is nearly double the national average of $14 \%$, suggesting that current interventions in prisons, focused on raising awareness, are not effective. Evidence based programs targeting tattooing and MSM are needed urgently to reduce the risk of HIV infected prisoners spreading infections to their communities after release.
\end{abstract}

Keywords: HIV and AIDS, prevalence, prisons, risk behaviours, Zambia.

\section{INTRODUCTION}

Like in so many other countries, there is a growing concern amongst public health authorities and Government in Zambia, that despite the rapid development of interventions in response to the AIDS epidemic over the last three decades, prisoners continue to receive less protection against $\mathrm{HIV}$ and other infectious diseases compared to communities outside prison.

Given the fact that most inmates are in prison for only a short period of time, HIV infection acquired inside can easily be transmitted outside. It has therefore been recognized that giving protection to prisoners is in the long run giving protection to the broader community. Prison populations have therefore been identified as a key population in the world wide strategy to control the spread of HIV infection [1].

*Address correspondence to this author at the IN BUT FREE Prisons Project, P O Box 22521, Kitwe, Zambia; Tel: 260977 724188;

E-mail: oscar.simooya@cbu.ac.zm
Two major studies have been conducted in Zambian prisons since the advent of the HIV and AIDS epidemic. The first study in 1988/9 reported an HIV seroprevalence of $16 \%$, a prevalence rate similar to the then national average of $16 \%$ [2]. Major risk behaviours identified were male to male sex (MSM) and tattooing.

In response to these findings, the country's prisons adopted the policy of the Ministry of Health's National AIDS Council whose major thrust was an aggressive awareness campaign and promotion of behavioural change. However, because male to male sex (MSM) is a criminal offence in the country [3] no condoms are distributed in Zambian prisons.

A decade later in 1998/9, the HIV prevalence rate in prisons had gone up to $27 \%$, much higher than the national average of $19 \%$ [4]. The new findings resulted in the endorsement of the country's national AIDS policies which had by now included the promotion of voluntary counseling and testing (VCT) and the provision of anti retroviral therapies (ARTs) for those with HIV infection [5].

This study, the third in the series, was designed to collect accurate and up to date information on risk behaviours and 
prevalence of HIV and other blood borne infectious diseases, health seeking behaviours and access to HIV and AIDS services.

\section{METHODS}

The survey was a cross sectional study of a sample of the 14,500 inmates living in 7 of Zambia's major prisons; Chipata, Kamfinsa in Kitwe, Livingstone, Lusaka Central, Mansa, Mongu, Mukobeko in Kabwe and Solwezi.

Sample size was determined using the formula, $\mathrm{n}=\mathrm{t}^{2} \times \mathrm{p}(1-\mathrm{p}) / \mathrm{m}^{2}$, where $\mathrm{n}$ is the required sample size, $\mathrm{t}=$ confidence level at $95 \%, \mathrm{p}=$ estimated prevalence, and $\mathrm{m}=$ margin of error. Using $27 \%$ as estimated prevalence of prisoners with HIV infection, a sample size of 303 , rounded up to 350 per prison to allow for laboratory results that might not have matching questionnaires and other data collection problems, a total sample of 2, 450 for all 7 prisons was proposed.

The survey protocol was approved by the Ethical Committee of the Ministry of Health and was voluntary, confidential and anonymous. All prisoners who did not participate in the survey were offered voluntary counselling and testing (VCT) and those testing positive were linked to appropriate services.

HIV infection was determined using a fourth-generation HIV $1 / 2 / O$ enzyme linked immunoassay (ELISA) test, Vironostika HIV Uniform 11-Plus 0 (BioMerieux, France) followed by testing all HIV positive samples with an independent HIV 1/2/O ELISA test Enzygnost* Anti-HIV 1/2 Plus (Dade Behring).

Samples testing positive on ELISA test 1 and negative on ELISA test 2 (discordant results) were retested again and if still discordant the specimen was submitted to a tie-breaker using a Western Blot assay, Western Blot 2.2 (MP Diagnostics ${ }^{\mathrm{TM}}$ ).

For the diagnosis of syphilis, all specimens testing positive using Rapid Plasma Reagin (RPR) test (Omega Diagnostics, UK) were retested using Treponema Pallidum Haemagglutination Assay (TPHA), Omega Diagnostics, UK to confirm the final diagnosis of syphilis.
Knowledge, attitudes, practices, risk behaviours and access to HIV and AIDS services were determined using a pre tested semi structured questionnaire. The results of HIV testing were linked to questionnaire responses using a duplicate of a randomly assigned study number.

\section{RESULTS}

\section{Study Population}

The survey was conducted between April 2009 and July 2010. A total number of 2, 244 prisoners, $92 \%$ of required sample size, volunteered to participate in the survey. The majority $(88.2 \%)$ of participants were aged between $15-44$ years while $90(4 \%)$ were aged above 55 years. Of the total number in the survey, $184(8.2 \%)$ were women.

Overall the survey sample was evenly distributed between those coming from rural areas and those from urban areas. One thousand one hundred and ten (49.5\%) participants were living in rural areas before imprisonment, while $1,131(50.5 \%)$ came from urban areas.

Eight hundred and ninety seven (897) or $40 \%$ of prisoners were on remand (pre-trial) prisoners while 360 $(16 \%)$ were serving sentences of ten years or more. Half of the participants/prisoners, $49.8 \%$, had spent less than a year in prison at the time of the survey while for $1,674(75 \%)$ this was the first time in prison.

\section{HIV Seroprevalence in Zambian Prisons $2010(n=2244)$}

A total of 609 (27.4\%) participants were HIV seropositive. At Lusaka Central Prison, 42.1\% of participants had HIV infection while Solwezi had the lowest number of prisoners with HIV infection, 33 (12.7\%) (see Table 1 below).

The age of participant and gender of participants were significantly associated with HIV status. In the 35-44 years age group, $195 / 538(36.2 \%)$, prisoners had HIV infection whilst in those aged 15-24, 69/436 (15.8\%) $(\mathrm{p}<0.0001)$, were seropositive. Amongst female participants, 78 (43.3\%) of those in the survey had HIV infection compared to 2039 $(26.0 \%)$ in male subjects $(\mathrm{p}<0.0001)$.

Marital status was associated with HIV result. Forty seven out of $98(48 \%)$ of the female prisoners who were

Table 1. Distribution of HIV Prevalence in 7 Zambian Prisons, 2010.

\begin{tabular}{|c|c|c|c|c|c|c|}
\hline \multirow{3}{*}{ Prison } & \multicolumn{4}{|c|}{ HIV Serostatus } & \multirow{3}{*}{ Chi Square } & \multirow{3}{*}{ P Value } \\
\hline & \multicolumn{2}{|c|}{ Negative } & \multicolumn{2}{|c|}{ Positive } & & \\
\hline & Number & $\%$ & Number & $\%$ & & \\
\hline Chipata & 254 & 73.8 & 90 & 26.2 & & \\
\hline Kamfinsa & 257 & 73.9 & 91 & 26.1 & & \\
\hline Livingstone & 251 & 72.5 & 95 & 27.5 & & \\
\hline Lusaka Central & 198 & 57.9 & 144 & 42.1 & & \\
\hline Mukobeko & 247 & 70.8 & 102 & 29.2 & & \\
\hline Mongu & 176 & 76.5 & 54 & 23.5 & & \\
\hline Solwezi & 227 & 87.3 & 33 & 12.7 & & \\
\hline Total & 1610 & 72.6 & 609 & 27.4 & 68.25 & $<.0001^{*}$ \\
\hline
\end{tabular}

Notes: The chi square and $\mathrm{P}$ values are based on the Kruskal-Wallis test that rows are identically distributed in an $\mathrm{r} \times 2$ cross-table. $*=$ significant result. 
widowed were at the same time HIV infected compared to $364 / 1224(29.7 \%)$ in those who were married at the time of coming to prison $(\mathrm{p}<0.0001)$.

Residence prior to coming to prison was associated with HIV result, $347 / 1115$ (31.1\%) of those infected with HIV coming from urban areas compared to $261 / 1101(23.7 \%)(p<0.0001)$, in those living in rural areas before coming to prison.
There was no association between having HIV infection and level of education, imprisonment category (whether participant was remand or not), time spent in prison and whether one had been in prison before or not (see Table $\mathbf{2 a}$ and $\mathbf{2 b}$ below).

Only $35(1.6 \%)$ prisoners agreed that they had sex with someone in prison. However, 1047 (47.1\%) participants said a few prisoners were involved in MSM while 533 (24.1\%) reported that many were involved.

Table 2a. Demography of Inmates in Zambian Prisons and Result of HIV Test $2010(n=2244)$.

\begin{tabular}{|c|c|c|c|c|c|}
\hline \multirow{2}{*}{ Characteristic } & \multicolumn{2}{|c|}{ HIV Serostatus } & \multirow{2}{*}{ Total } & \multirow{2}{*}{ Chi Square } & \multirow{2}{*}{ P Value } \\
\hline & Negative & Positive & & & \\
\hline \multicolumn{6}{|l|}{ Age } \\
\hline$(15-24)$ years & 367 & 69 & 436 & & \\
\hline$(25-34)$ years & 696 & 285 & 981 & & \\
\hline$(35-44)$ years & 343 & 195 & 538 & & \\
\hline$(45-55)$ years & 111 & 50 & 161 & & \\
\hline$>55$ years & 81 & 9 & 90 & & \\
\hline Total & 1598 & 608 & 2206 & 66.35 & $<.0001^{*}$ \\
\hline \multicolumn{6}{|l|}{ Gender } \\
\hline Female & 102 & 78 & 180 & & \\
\hline Male & 1508 & 531 & 2039 & & \\
\hline Total & 1610 & 609 & 2219 & 24.82 & $<.0001 *$ \\
\hline \multicolumn{6}{|l|}{ Level of Education } \\
\hline Primary level & 714 & 273 & 987 & & \\
\hline Secondary level & 666 & 258 & 924 & & \\
\hline College level & 60 & 25 & 85 & & \\
\hline University level & 19 & 4 & 23 & & \\
\hline None at all & 142 & 49 & 191 & & \\
\hline Total & 1601 & 609 & 2210 & 1.75 & 0.7817 \\
\hline \multicolumn{6}{|l|}{ Marital Status } \\
\hline Married & 860 & 364 & 1224 & & \\
\hline Divorced/separated & 198 & 94 & 292 & & \\
\hline Widowed & 51 & 47 & 98 & & \\
\hline Cohabiting with a steady partner & 42 & 13 & 55 & & \\
\hline Single/Never married & 454 & 89 & 543 & & \\
\hline Total & 1605 & 607 & 2212 & 60.95 & $<.0001^{*}$ \\
\hline \multicolumn{6}{|l|}{ Other Sexual Partners } \\
\hline Yes & 775 & 384 & 1159 & & \\
\hline No & 501 & 148 & 649 & & \\
\hline Total & 1276 & 532 & 1808 & 21.36 & $<.0001^{*}$ \\
\hline \multicolumn{6}{|c|}{ Employment Status Before Imprisonment } \\
\hline Unemployed & 124 & 40 & 164 & & \\
\hline Farmer & 364 & 82 & 446 & & \\
\hline Self employed & 592 & 278 & 870 & & \\
\hline Employee & 432 & 196 & 628 & & \\
\hline Employer & 7 & 2 & 9 & & \\
\hline Still at school & 85 & 10 & 95 & & \\
\hline Total & 1604 & 608 & 2212 & 46.22 & $<.0001 *$ \\
\hline
\end{tabular}

Notes: The chi square and $\mathrm{P}$ values are based on the Kruskal-Wallis test that rows are identically distributed in an $\mathrm{r} \times 2$ cross-table. ${ }^{*}=$ significant result. 
Table 2b. Demography (Continued) of Inmates in Zambian Prisons and Result of HIV Test 2010 (n = 2244).

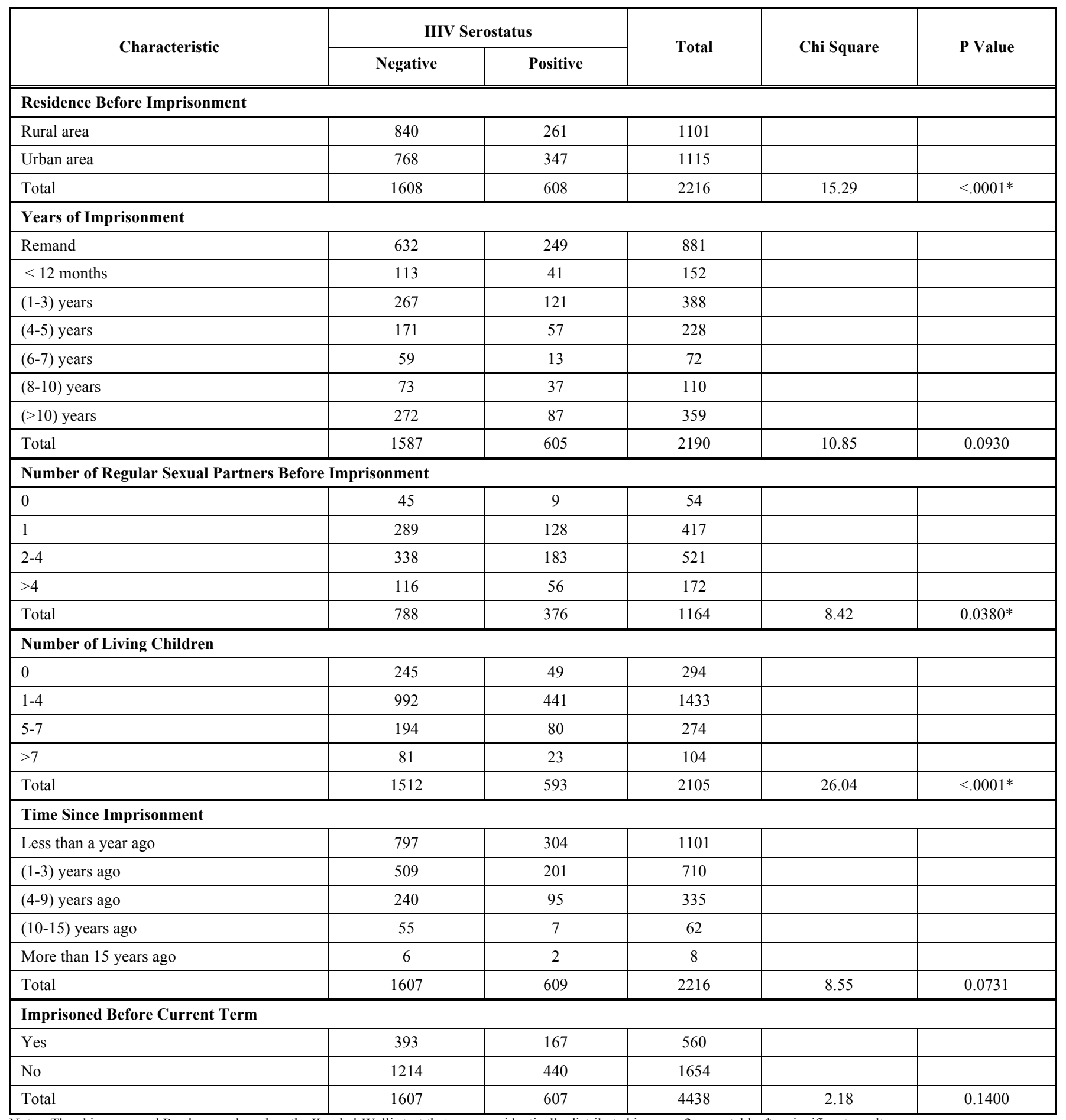

Notes: The chi square and $\mathrm{P}$ values are based on the Kruskal-Wallis test that rows are identically distributed in an $\mathrm{r} \times 2$ cross-table. ${ }^{*}=$ significant result.

Although over $40 \%$ of participants reported sharing shaving equipment no association was found with HIV status. However, tattooing was significantly associated with being HIV seropositive. Of 132 prisoners who had been tattooed in prison, $46(34.8 \%)$ had HIV infection compared to $26.9 \%(\mathrm{p}<0.0001)$ in those who had never been tattooed.

The most common instrument used for tattooing are needles reported by $101(76.5 \%)$ of the 132 prisoners who had been tattooed in prison.

\section{Prevalence of Syphilis}

One hundred out of 2216 (4.5\%) participants were found with syphilis antibodies and this was significantly associated with having HIV infection. Of the 100 prisoners with syphilis, $47 \%$ were also found to have HIV infection, compared to $26.5 \%(\mathrm{p}<0.0001)$ in those who were negative for syphilis.

\section{Knowledge, Attitude and Practices}

Overall, many prisoners had knowledge about HIV and AIDS and its mode of transmission. Of 2214 participants 
interviewed, 2201 (99.4\%), had heard of AIDS and 2070/2216 (93.4\%) knew that you could reduce the chances of getting HIV infection by having only one partner. Over $70 \%$ of prisoners in the survey considered HIV and AIDS a serious problem in prisons while $44.1 \%$ were worried that they risked getting HIV infection in prison.

Many prisoners, 1924/2213 (86.9\%), said condoms could protect one from getting HIV infection but over $90 \%$ said "NO" to condom distribution in prisons. A total of $1458 / 2213(66 \%)$ prisoners feared the possibility of getting HIV infection from a mosquito bite, while $97 \%$ and $95 \%$ said you could get HIV infection by sharing razor blades, or by tattooing respectively, $82 \%$ said a pregnant mother could give HIV infection to her unborn baby and $83.9 \%$ of prisoners said there was no cure for AIDS.

\section{Access to HIV and AIDS Services}

Half of the participants in the survey, 1110/2214, had had voluntary counselling and testing (VCT). Out of 1106 participants who had VCT, $747(67.5 \%)$, had VCT at the prison where they were incarcerated. One thousand two hundred and sixty seven (1267) participants out of 1976 (64.1\%), knew their status.

A diagnosis of TB was associated with having a positive HIV test. Out of a total of 2197 respondents, $156(7 \%)$ had TB. Eighty five (54.5\%) prisoners with TB were at the same time HIV seropositive compared to 519/2041 (25.4\%) $(p<0.0001)$ in those without TB.

The only information accessed by at least $50 \%$ of participants was that on VCT. Less than $50 \%$ of respondents had seen materials on each of the following; AIDS policy, condom use, ART, MSM and injection drug use (IDU).

The major source of HIV and AIDS support in the seven prisons were fellow prisoners mentioned by $55.5 \%$ of respondents, nongovernmental organisations $55.1 \%$, health service providers $37 \%$, prison personnel $34.3 \%$ and faith based organisations, $34.1 \%$. Condoms and sterile needles were not available.

Eleven out of $161(6.8 \%)$ female prisoners in the survey were pregnant at the time of incarceration and 9 gave birth whilst in prison. Seven out of 13 women prisoners reported receiving prevention of mother to child transmission (PMTCT) of HIV service in prison. Twenty female prisoners said they were living with a child in prison, out of whom 5 received formula feed. Ninety three (93) out of 141 (66\%) female prisoners who responded to this question said they accessed gynaecological services whilst in prison.

\section{DISCUSSION}

This survey, the third since AIDS was identified as a serious public health problem by the Government in Zambia, found a high HIV prevalence rate of $27 \%$ which is almost double the national average of $14.3 \%$ reported in the Zambia Demographic and Health Survey (ZDHS) of 2007 [6] This finding suggests that current interventions in prisons may not be yielding desired results.

Over one in four prisoners surveyed in this study had HIV infection. Lusaka Central prison, a facility located in the heavily urbanised capital city of Zambia had the highest prevalence rate of $42.1 \%$ while Solwezi prison, situated in the rural areas of the country had the lowest rate with $12.7 \%$ of prisoners being HIV seropositive.

Age of participant and gender was strongly linked to the result of HIV testing. Prisoners aged between 35-44 years old had the highest proportion, $36.2 \%$, of those with HIV infection while female prisoners had a significantly high HIV prevalence of $43.3 \%$.

Of 350 participants sampled at Lusaka Central, 238 $(68 \%)$ were pre trial or remand prisoners. Therefore, it could be argued that the higher prevalence of HIV infection obtained at this prison was due to the presence of a large number of remand prisoners who are often in and out of prison.

However, when compared to the rate of HIV infection in participants of other imprisonment status, no significant difference was found between those on remand and those serving long sentences. Furthermore, like in our findings of 1998, we did not find any association between actual time spent in prison and HIV status suggesting a high risk environment inside prisons equivalent to that obtaining outside.

Being widowed, having other sexual partners apart from an immediate spouse and being salaried or in self employment were all strongly associated with having HIV infection. Use of clear beer or lagers and traditional beers before coming to prison were also linked to HIV seropositivity. However, no linkages were found between levels of education, previous incarceration and outcome of HIV testing.

The relationship between sexually transmitted infections (STI) and HIV infection has been well documented [7-9] Having an STI increases the risk of HIV infection. We confirmed this association in our survey where almost half of those who tested positive for syphilis antibodies and those who had been treated for an STI were at the same time HIV seropositive. Similarly, tuberculosis (TB) is one of the commonest opportunistic infections in those living with HIV and AIDS [10, 11] Over half of the participants with a diagnosis of TB had HIV infection.

When taken together, our findings largely mirror that of the epidemic at national level where HIV transmission is typically a heterosexual phenomenon and is highest in urban areas and low in the rural parts of the country, is higher in women than in men, those aged 30-39 years and in individuals with high sexual activity.

Therefore, it would appear that most prisoners with HIV infection in our prisons could have acquired their infection before coming to prison. However, the possibility of a large number of prisoners being infected inside cannot be ruled out.

Injecting drug use (IDU) and male to male sex (MSM) are common risk behaviours in prisons and are known to be efficient modes for the transmission of HIV infection $[12,13]$ But, because IDU and MSM are illegal and criminal offences in many sub Saharan African countries including Zambia, information about their contribution to the high HIV prevalence rates in prisons are often difficult to come by [14]. 
Only $35(1.6 \%)$ prisoners agreed in one to one interviews that they had engaged in MSM whilst in prison. This finding is within the range of $0-18 \%$ we found in previous studies. We however believe that this is not a true reflection of the actual numbers of prisoners engaging in MSM. When we asked participants to indicate how common the practice was at their prison, 1040 or $47.1 \%$ said a few were involved while $533(24.1 \%)$ said many were involved. Amongst the 35, who said they had MSM in prison, no significant association was found between having HIV infection and MSM.

Tattooing has been recognized as a risk factor for HIV transmission and is common in prisons throughout the world $[15,16]$ Following the survey of 1998 , tattooing was banned in all Zambian prisons [17]. Nearly $66.6 \%$ of participants in this survey said tattooing occurred at their prison, while 132 admitted to having been tattooed whilst in prison. Being tattooed in prison was significantly associated with having HIV infection. To our knowledge this is the first report of such an association in Zambian prisons.

Overall, despite the high HIV seroprevalence rate in prisons, many prisoners were knowledgeable about HIV and AIDS and had sufficient knowledge to protect them against acquiring HIV infection. This awareness includes the knowledge that you could get infected by sharing razor blades and by tattooing. Over $80 \%$ of the participants knew that you could not get HIV by sharing food, while $72.2 \%$ correctly said that a healthy looking person could be carrying the AIDS virus.

In addition to high levels of HIV and AIDS awareness, more than half of the participants had undergone voluntary counselling and testing (VCT), a procedure recognised in Zambia as the entry point for AIDS care $[18,19]$ It is said that knowing one's HIV status saves as a motivating factor for behaviour change and also helps as a link to various HIV and AIDS services.

Of those who had VCT, over $67.5 \%$ accessed the service at the prison of their incarceration. Furthermore, over $70 \%$ of the participants knew about the availability of ART medicines at their prison. Our findings suggest that VCT is now available to most prisoners and efforts to increase uptake of the service must be made.

We did not find any "harm reduction" services, in any of the seven prisons in the survey. Harm reduction is a concept that has been used successfully to minimise HIV transmission and morbidity in several European prisons [2022] Under harm reduction public health considerations are used to navigate past the serious moral and legal questions posed by some of the risk behaviours in prisons.

For example, condoms are provided to guard against sexual transmission of HIV, while clean needles and syringes are made available to IDUs. In our series of surveys in Zambian prisons, prisoners and prison staff continue to oppose the distribution of condoms in prison as it is said availability of condoms would promote promiscuity [23].

We therefore favour a multi pronged evidence based intervention that must be as sensitive as possible to the social and cultural values of the larger community outside whilst mindful of the reality of the various hazards at play in prisons. This being the case, it is clear that for Zambian prisons, the complex moral, cultural and legal issues will need urgent consideration in order to arrive at programmes that will reverse the current HIV and AIDS picture in prisons. Government has an important role to play in this respect and will need to provide leadership in the quest to reverse the epidemic in prisons. We believe that sufficient information has been obtained in this and previous work in prisons to sufficiently guide the process.

\section{CONFLICT OF INTEREST}

The authors confirm that this article content has no conflict of interest.

\section{ACKNOWLEDGEMENTS}

This survey was funded by a consortium of cooperating partners including the World Health Organization (WHO), the Joint United Nations Programme on HIV and AIDS (UNAIDS), the United Nations Office on Drugs and Crime (UNODC) and the Global Fund for the fight against AIDS, Tuberculosis and Malaria (GFATM).

\section{REFERENCES}

[1] UNAIDS. At risk and neglected four key populations. 2006 report on the Global AIDS epidemic, Geneva, Switzerland, 2006; CAP 5; 105-122.

[2] Simooya OO, Maboshe MN, Hira SK, Mukunyandela M. A strategy for the prevention of HIV/AIDS in African prisons, Proceedings of 7 th International Conference on AIDS in Africa (ICASA), Marrakech, Morocco 1993.

[3] Government of the Republic of Zambia. Indecent practices between men. Laws of Zambia CAP 146(Penal Code); Section 158. Lusaka; Government Printers 1995.

[4] Simooya OO, Sanjobo N, Sijumbila, et al." Behind Walls”: A study of HIV/AIDS risk behaviours and seroprevalence in prisons in Zambia. AIDS 2001; 15(13): 1741-4.

[5] Copperbelt University Health Services. Conference Report: National Workshop on HIV and AIDS in Prisons. Tuskers Hotel, Kabwe, Zambia, 2000.

[6] Central Statistical Office (CSO), Ministry of Health (MoH), Tropical Diseases Research Centre (TDRC), University of Zambia and Macro International Inc. Zambia Demographic and Health Survey 2007. CSO and Macro International Inc. Calverton, Maryland, USA 2009.

[7] Nelson KE, Eiumtrakul S, Celentano D, et al. The association of herpes simplex type 2 (HSV-2), Haemophilus ducreyi, and syphilis with HIV infection in young men in northern Thailand. J Acquired Immune Defic Syndr Hum Retrovirol 1997; 16 (4): 293-300.

[8] Todd J, Grosskurth H, Changalucha J, et al. Risk factors influencing HIV infection incidence in a rural African population: a neglected case-control study. J Infect Dis 2006; 193 (3): 458-66.

[9] Ward H, Rönn M. Contribution of STI to the sexual transmission of HIV. Curr Opin HIV AIDS 2010; 5(4): 305-10.

[10] van Cleeff MR, Chum HJ. The proportion of tuberculosis cases in Tanzania attributable to human immunodeficiency virus. Int $\mathrm{J}$ Epidemiol 1995; 24 (3): 637-42.

[11] Boccia D, Hargreaves J, De Stavola BL, et al. The association between household socioeconomic position and prevalent tuberculosis in Zambia: a case-control study. PLoS One 2011; 6(6): e 20824.

[12] Nishioka S de A, Gyorkos TW. Radovanovic Z, et al. Tattoos as risk factors for transfusion-transmitted HIV seropositivity in a Yugoslav prison population. J Hyg Epidemiol Microbiol Immunol 1990; 34: 27-9.

[13] Sexually transmitted diseases surveillance among incarcerated men who have sex with men-an opportunity for HIV prevention. AIDS Educ Prev 2003; 15(Suppl A): 117-26.

[14] UNODC. HIV and Prisons in Sub-Saharan Africa: opportunities for action. UNODC, Vienna, Austria 2007. 
[15] Nishioka S de A, Gyorkos TW. Tattoos as risk factors for transfusion-transmitted diseases. Int $\mathrm{J}$ Infect Dis 2001; 5(1): 27-34

[16] Hellard ME, Aitken CK, Hocking JS. Tattooing in prisons-not such a pretty picture. Am J Infect Control 2007; 35 (7): 477-80.

[17] Zambia Prisons Service Report on HIV/AIDS situation in Zambian prisons, HIV/AIDS workshop, Zambezi Source Lodge, Kabwe, Zambia 2006

[18] National HIV/AIDS/STI/TB Council. The HIV/AIDS epidemic in Zambia. Where are we now? Where are we going? National/HIV/AIDS/STI/TB Council. Lusaka, Zambia 2004.
[19] Comprehensive HIV/AIDS Management Programme (CHAMP). Psycho social counselling manual. CHAMP. Lusaka, Zambia 2006.

[20] World Health Organisation (WHO). Status papers on drugs prisons and harm reduction. WHO, Copenhagen, Denmark 2005.

[21] Jürgens, R. Effectiveness of interventions to address HIV in prisons (Evidence for Action Technical Paper). Geneva: World Health Organization, UNAIDS and UNODC 2007.

[22] Hoover J, Jürgens R. Harm reduction in prisons: the Moldova Model. International Harm Reduction Programme. Open Society Institute. New York, USA 2009.

[23] Simooya OO, Sanjobo N. HIV/AIDS is still double sentence in prisons. BMJ 2006; 332: 119-120.

(C) Simooya et al.; Licensee Bentham Open.

This is an open access article licensed under the terms of the Creative Commons Attribution Non-Commercial License (http://creativecommons.org/licenses/by-nc/ 3.0/) which permits unrestricted, non-commercial use, distribution and reproduction in any medium, provided the work is properly cited. 